was given hypodermically. Pulse 128 ; respiration 46 ; temperature $10^{\circ}$. On the 11th one-sixtieth of a grain of digitalin in granules was ordered every four hours. The patient had a very bad night, coughing incessantly. The abdomen was very painful, and morphia had to be given again. This morning (April 12th), at 9 A.M., the patient had a sudden attack of dyspnoa, became very pale, and complained of intense pain in the abdomen. The dyspnoea and pallor became extreme, the abdominal pain persisting, and he died apparently from syncope.

Necropsy. - Both pleural cavities, practically obliterated by recent soft adhesions, specially thick on the upper surface of the diaphragm. Lungs tough and semi-solid in parts. Pericardial cavity completely obliterated at every point. Separation of pericardium impossible withont laceration of muscle. No unusual adhesions to mediastinal tissues, the inner surfaces of lungs being only softly adherent. The heart with attached pericardium weighed twenty-five ounces, and was clearly much enlarged, the right and left sides maintaining their normal proportions to each other. The cavities were all dilated, especially the ventricles. The muscle looked pale, and its line of demarcation from the pericardium was indistinct. A large papillary muscle in the leftventricleshowed distinct "pheasant-wing" markings. No hæmorrhage into the muscle. The aortic valves looked a little opaque and sodden, but were practically healthy. The mitral orifice admitted four fingers (obvious dilatation), but thevalve itself was quite normal. The right valves were healthy and the aorta normal. The peritoneal cavity was practically filled with fluid blood and clots; over forty ounces of fiuid were measured, and there would be a considerable quantity left after that in the recesses of the cavity. This fluid blood presented the ordinary characters of blood under such circumstances. Lying over the right lobe of the liver was a large clot the size and thickness of a full-time placenta. (The appearances were precisely such as one has seen in cases of laceration of the liver, for instance; and Dr. Barrs at once suspected rupture of that organ or of the spleen, but after a most prolonged search and injecting the abdominal vessels, and resorting to all the plans he could think of he was quite unable to find the source of the bleeding.) On the convex surface of the left lobe of the liver, and in contact with the abdominal wall, was a large patch of toughish-looking lymph. Between the lobulus quadratus and the left lobe there were also some soft recent adhesions, with hæmorrhage into them. The liver itself showed the ordinary "nutmeg change." Dr. Barrs carefully examined all the trunk branches of the abdominal aorta for aneurysm, but could find none. All the organs not referred to were healthy.

Remarks by Dr. BARns. - The case narrated affords in its essential conditions, though not in its mode of death, a striking example of one of the more immediately fatal cardiac complications to which acute rheumatism gives origin. In THE LANCET for 1881, I published a small series of cases of adherent pericardium of rheumatic origin terminating in death by cardiac dilatation, and expressed the opinion that this lesion ought in all probability to be regarded as an almost certainly fatal complication of rheumatic fever. The present case is one of unusual interest because the march of events can be fixed with greater exactitude than usually happens in hospital practice. When I saw the man eight weeks before he came into the hospital, he presented all the usual evidences of acute and recent pericarditis. When admitted the signs of pericarditis were not evident, and at the end of four weeks longer he is dead, with complete and firm obliteration of the pericardial cavity. So that it is shown, by this case at least, that in the course of three months an attack of acute rheumatic pericarditis, with its attendant myocarditis, is able to bring about a fatal condition, characterised mainly by extreme but anomalous manifestations of cardiac dilatation and alternate failure. The immediate cause of death was the intra-peritoneal hæmorrhage, for which, as I have said in the body of the report, I was unable at the necropsy to find any cause whatever. But apart from this, which I cannot but regard as an accident, the case was pursuing a rapidly downward course, the grave disturbance of the circulatory apparatus progressing steadily towards a fatal termination, in spite of an energetic and varied treatment. I am not acquainted with any recorded case of intra-peritoneal hremorrhage ending fatally, for which no obvious cause could be found; neither am I aware that it has been observed to occur in cases of cardiac disease, either as a result of renous stasis or any of the other conditions which give rise to hamorrhages in other localities.

\section{THE SAMARITAN HOSPITAL FOR WOMEN, BELFAST.}

THREE CASES OF RARE OCCURRENCE.

(Under the care of Dr. MCMORDIE.)

CASE 1. Congenital deficiency of the recto-vaginal septum; operction; cure.-M. H-, aged twenty-five, single, appeared in the out-patient department on April 15th. She gave the following history. The catamenia appeared at the age of sixteen, and since then she has only menstruated seven times at irregular intervals. She had not "seen anything" for three years. She complained of being nervous, of heats and colds, and of pain in the vagina and lower back. Owing to her irritable condition it was inmossible to make a vaginal examination without an anæs thetic. The following day, having been put under the influence of chloroform, an examination was made. The vagina was found to be very small and the hymen intact. A finger of one hand bein passed into the vagina, lumps of hardened fæecs were found in the upper part, close to the cervix uteri. A finger of the other hand being introduced into the rectum, it passed through an opening in the vaginal septum and met the other finger in the vagina. 'The opening was about the size of a sixpence, and situated about one inch from the anus. The edges were pared freely towards the vagina and brought together by silver wire. The union was perfect, and she was discharged cured three weeks from her admission.

There are two points of interest in this case: (1) The long time the opening had existed without being detected. (2) The menstrual fluid may have passed unnoticed by this opening instead of by the aperture in the hymen.

CASE 2. Foreign body in the rectum; remoral; recovery. - K. H-, aged forty-four, married; twelve children and two miscarriages, the last one a miscarriage at three months, two months before her admission to the Samaritan Hospital on March 15th. For three weeks previously she had vomited after every meal. She complained of severe pain in the hypogastric region. There was a movable abdominal tumour about the size of an adult head. An examination by the finger per rectum discovered a hard body lodged in the anterior wall, on a level with the promontory of the sacrum. There was a considerable amount of swelling and tenderness at this point, so that with some difficulty the finger could be passed beyond it. A speculum forceps was passed up, and the body seized and removed. It proved to be a thin, flat piece of bone, triangular in shape, one-third of an inch at the base, and the sides of the triangle measuring half an inch. It appeared to be a portion of the skull of some animal. The bowel was cleared out by copious enemata, and the patient recovered.

CASE 3. Rapid development of a thyroid cyst.-E. Ksingle, aged twenty, was aumitted to the wards on swollen and tense, with an elastic feel, and about the size of a small orange. It had developed very rapidly, the girl stating that she first noticed it about seven days before her admission. The cellular tissue surrounding it was inflamed and œedematous; it was difficult to be certain of the nature of the contents, so an exploring trocar was passed and some clear serons fluid drawn off. There was now no doubt that the swelling was an acute bronchocele, confined to the right lobe. The isthmus and the left lobe were not affected. The swelling was tapped, and two ounces of clear fluid drawn off. Nothing was injected. The girl was a native of Portrush, and had been at service in Belfast for eigliteen months. When admitted she was in a very anæmic condition. She left the hospital on March 16th much improved in health, and there was no appearance of any returning enlargement of the thyroid.

The British Association.-At a meeting held in the Mayor's room at the Town Hall, Leeds, on the 20 th inst., it was resolved to renew the invitation sent last year to the British Association, to hold their meeting in that town in 1890 , and to raise, for expenses, a guarantee fund of $£ 5000$. 